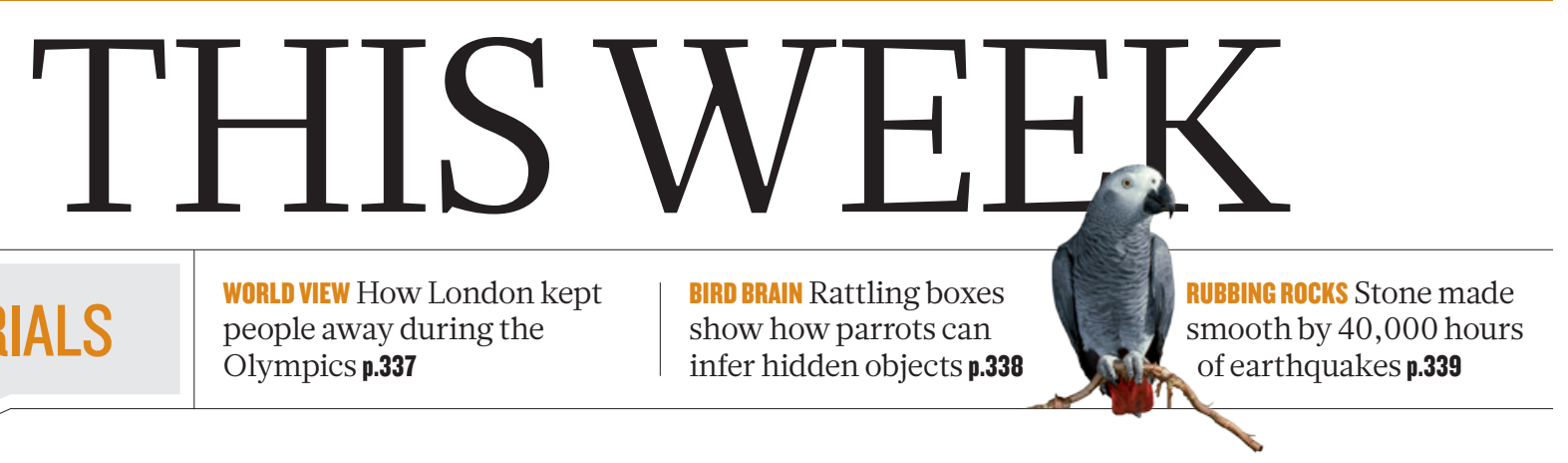

EDITORIALS people away during the show how parrots can infer hidden objects $\mathbf{p . 3 3 8}$

\title{
Through the gaps
}

\section{A 20-year campaign of scientific fraud says as much about the research community as it does about the perpetrator. The system that allowed such deception to continue must be reformed.}

$\mathrm{M}$ any questions are provoked by the shocking case of Yoshitaka Fujii, the Japanese anaesthesiologist who seems likely to set a record for the highest number of retracted papers by a single scientist. His entire list of publications has come under scrutiny: his trail of deception seems to have wound through almost 200 scientific articles over 20 years. Twenty years! How could it go on for so long?

As the News story on page 346 details, Fujii seems to have fabricated multiple studies wholesale, in some cases inventing participants. Nobody noticed - not his collaborators, funders, home institutions or journal editors. Or at least, nobody took action.

In retrospect, as in all cases of scientific fraud, the bulk of the questions will, rightly, focus on how to make sure that it cannot happen again. That, and why so much time passed before anyone investigated how Fujii was publishing clinical studies at impossible speed.

Fujii pulled the wool over the eyes of many different people - chief among them, various employers, whom he also falsely claimed had approved his studies, and journal editors. (One editor has publicly issued a mea culpa.) Perhaps most puzzling is that Fujii fooled his co-authors, one of whom published dozens of papers with him. The co-authors say that they had no suspicions; the Japanese Society of Anesthesiologists, which had a key role in exposing Fujii's fraud, is investigating.

But let's be honest. Even assuming that any co-author had suspicions, the current system means that it would not have been easy to raise the alert. It can be difficult to document a colleague's errant ways, and whistle-blowers might put their own careers at risk by angering a senior member of the field.

Those who inform authorities about other types of fraud sometimes get rewards. For example, the US government last week paid out its and probably the world's - biggest ever payment to a whistle-blower. The former banker, who was jailed for his own role in a tax-evasion scandal, received US\$104 million. Observers - especially lawyers are pointing out that such windfalls might be the only way to encourage more insiders to put their necks on the line, which remains the most effective way to protect against such crimes.

That method is probably unworkable in science. Funders won't have that kind of cash to throw at scientific whistle-blowers. And imagine the uproar, not least in these pages, if whistle-blowers routinely got payouts bigger than the grants available for science projects through competitive peer review.

In the tax-evasion case, the figure was justified because it was only a small fraction of what the US government was able to recoup. But governments should also consider the amount of waste incurred by research fraud, especially when that fraud is carried out over decades and enshrouded in the scientific literature. On financial grounds alone, there are sound reasons for the authorities to increase the resources

invested in efforts to limit academic misconduct, without the need to provide monetary rewards.

Japan, for example, could make it easier for whistle-blowers to take their claims to an external body, rather than to their employers. In theory, the country already has such a system. But in practice, agencies at the relevant ministries merely forward claims to the institu-

"On financial grounds alone, there are sound reasons for the authorities to increase the resources invested in efforts to limit academic misconduct."

misconduct."
tions involved, leaving whistle-blowers vulnerable.

In the wake of the latest scandal, there are signs of positive change. The Japanese Society of Anesthesiologists was so frustrated at the lack of an effective whistle-blowing mechanism that it plans to establish one. A group of 23 journal editors deserves credit for effectively, if belatedly, rooting out Fujii's problematic publications. And statistical approaches to evaluating results - such as those used to show that Fujii's data were far too perfect - are becoming more familiar, more readily available and, hopefully, more accepted as a legitimate way to audit published findings and raise red flags where necessary.

It is important to note that although this latest case of fraud seems (again) to be an anomalous, extreme example involving one individual, the problems that allowed it to persist are endemic in scientific communities around the world. It is equally important to say (again) that they must be addressed in comprehensive fashion.

\section{Extreme weather}

\section{Better models are needed before exceptional events can be reliably linked to global warming.}

A s climate change proceeds - which the record summer melt of Arctic sea-ice suggests it is doing at a worrying pace nations, communities and individual citizens may begin to seek compensation for losses and damage arising from global warming. Climate scientists should be prepared for their skills one day to be probed in court. Whether there is a legal basis for such claims, such as that brought against the energy company ExxonMobil by the remote Alaskan community of Kivalina, which is facing coastal erosion and flooding as the sea ice retreats, is far from certain, however. So lawyers, insurers and climate negotiators are watching with interest the emerging ability, arising from improvements in climate models, 
to calculate how anthropogenic global warming will change, or has changed, the probability and magnitude of extreme weather and other climate-related events. But to make this emerging science of 'climate attribution' fit to inform legal and societal decisions will require enormous research effort.

Attribution is the attempt to deconstruct the causes of observable weather and to understand the physics of why extremes such as floods and heatwaves occur. This is important basic research. Extreme weather and changing weather patterns - the obvious manifestations of global climate change - do not simply reflect easily identifiable changes in Earth's energy balance such as a rise in atmospheric temperature. They usually have complex causes, involving anomalies in atmospheric circulation, levels of soil moisture and the like. Solid understanding of these factors is crucial if researchers are to improve the performance of, and confidence in, the climate models on which event attribution and longer-term climate projections depend.

Event attribution is one of the proposed 'climate services' seasonal climate prediction is another - that are intended to provide society with the information needed to manage the risks and costs associated with climate change. Advocates of climate services see them as a counterpart to the daily weather forecast. But without the computing capacity of a well-equipped national meteorological office, heavily model-dependent services such as event attribution and seasonal prediction are unlikely to be as reliable.

At a workshop last week in Oxford, UK, convened by the Attribution of Climate-related Events group - a loose coalition of scientists from both sides of the Atlantic - some speakers questioned whether event attribution was possible at all. It currently rests on a comparison of the probability of an observed weather event in the real world with that of the 'same' event in a hypothetical world without global warming. One critic argued that, given the insufficient observational data and the coarse and mathematically far-from-perfect climate models used to

generate attribution claims, they are unjustifiably speculative, basically unverifiable and better not made at all. And even if event attribution were reliable, another speaker added, the notion that it is useful for any section of society is unproven.

Both critics have a point, but their pessimistic conclusion - that climate attribution is a non-starter - is too harsh. It is true that many

"To make this emerging science of 'climate attribution' fit to inform legal and societal decisions will research effort." require enormous

climate models are currently not fit for that purpose, but they can be improved. Evaluation of how often a climate model produces a good representation of the type of event in question, and whether it does so for the right reasons, must become integral to any attribution exercise. And when communicating their results, scientists must be open about shortcomings in the models used.

It is more difficult to make the case for 'usefulness'. None of the industry and government experts at the workshop could think of any concrete example in which an attribution might inform business or political decision-making. Especially in poor countries, the losses arising from extreme weather have often as much to do with poverty, poor health and government corruption as with a change in climate. The United Nations is planning to set up a fund with the aim of reducing loss and damage due to climate change, but the complexity of such issues is making negotations difficult.

These caveats do not mean that event attribution is a lost cause. But they are a reminder that designers of climate services must think very clearly about how others might want to use the knowledge that climate scientists produce. That could be a task for social scientists, who have good methods for analysing decision-making and social transactions. They need to be more involved in shaping the production and dissemination of climate knowledge.

\section{Return to sender}

\section{The bid to halt air transport of lab animals poses an imminent threat to biomedical research.}

\section{$\mathrm{T}$} his week, the campaign group People for the Ethical Treatment of Animals (PETA) will take another step forward in its longrunning, and increasingly successful, campaign to halt the transport by air of animals destined for the laboratory. It will announce that FedEx and UPS, the world's two largest cargo carriers, have written to it to affirm existing policies restricting the transport of most lab animals (see page 344). On the face of it, this seems pretty inconsequential. After all, neither carrier moves many research animals, and there are plenty of cargo firms that could make up any shortfall caused by PETA's pressure.

But appearances are deceptive: there could yet be an immediate and highly problematic effect. UPS has also said that it plans to change its policy soon to restrict the transport of amphibians, insects, crustaceans, molluscs and fish - all of which it allows at present. This could disrupt everything from the availability of the important frog model, Xenopus - three of whose major US-based suppliers rely on UPS next-day delivery - to the provision of the fruitfly Drosophila to international clients by the Bloomington Drosophila Stock Center at Indiana University.

And with PETA increasing the pressure, who is to say whether FedEx would not follow its arch-rival's lead and halt the transport of insects and other lower species? As with UPS, the effect would be huge. To name just a couple: FedEx currently ships fruitflies from suppliers including the Drosophila Species Stock Center at the University of California, San Diego, and Carolina Biological Supply in Burlington,
North Carolina. The latter uses FedEx to ship Drosophila, along with crayfish, mussels and many other non-mammals, to science teachers.

If this is not enough to make scientists sit up and take notice, they might consider the use of lab rodents, now under threat in India from a PETA campaign to halt the transport of all research animals by Air India. The National Institute of Nutrition in Hyderabad, a major government supplier of specialized mice, relies on the airline. As PETA undertakes a systematic push to target all major cargo carriers, scientists in any country who rely on air freight to deliver rodents should be on notice that their turn may be next. Of course, in the increasingly global world of science it is already, in many senses, everyone's turn.

The pronouncements by FedEx and UPS, together with similar bans on animal movement made previously by airlines and ferry companies, are especially worrying because they indicate that biomedical researchers in many different countries, through reticence and passivity, are losing the battle for the hearts and minds of the public when it comes to the need for, and legitimacy of, animal research. Why else would high-profile companies be willing to indicate, however implicitly, that they want no part in a transportation infrastructure that is crucial to global biomedical science?

If individual scientists wait until they are personally affected - until the day when that mouse carefully bred in Shanghai or Singapore or Stockholm cannot be had for love nor money in San Francisco - it will be long past too late to mount the vigorous, public campaign in defence of animal research that is so sorely called for at this moment.

As researchers join this battle - and join it, they must - they should, as a first step, work through their institutions, academic soci- $\rightarrow$ NATURE.COM To comment online, click on Editorials at: go.nature.com/xhunqu eties and umbrella groups to make an urgent, articulate, unified case to UPS and FedEx that the shipping of animals, mammalian and otherwise, is essential for both biomedical research and scientific education. 